Fetal Diagnosis and Therapy
Fetal Diagn Ther 2014;36:117-128

DOI: $10.1159 / 000359969$
Received: January 7, 2014

Accepted after revision: January 23, 2014 Published online: February 21, 2014

\title{
Placental Pathology in Early-Onset and Late-Onset Fetal Growth Restriction
}

\author{
William Mifsud Neil J. Sebire \\ Department of Paediatric Histopathology, Great Ormond Street Hospital, London, UK
}

\section{Key Words}

Placental pathology · Growth restriction · Pre-eclampsia

\begin{abstract}
Several histopathological features are found more frequently in placentas from pregnancies complicated by fetal growth restriction (FGR), including villous infarction, maternal vascular changes and villous morphological alterations, although around one quarter of placentas associated with FGR lack any morphological abnormality on routine examination. Since similar changes may also affect clinically uncomplicated pregnancies, the positive predictive value of such findings for pathological FGR in an unselected case remains low. However, the pattern of placental pathologies varies with clinical subgroup. The combination of placental bed and parenchymal lesions in FGR with abnormal uterine artery Doppler velocimetry is essentially identical to preterm pre-eclampsia (PET), and there is an association between FGR with abnormal umbilical artery Doppler findings and lesions of fetal stem arteries and terminal villous hypovascularity. Conversely, placentas from pregnancies complicated by PET or FGR presenting at or near term have a significantly lower frequency of histological abnormalities compared to early-onset disease and absence of a distinctive biochemical
\end{abstract}

profile. The histological placental findings in FGR are therefore varied, from morphologically unremarkable through to severe uteroplacental vasculopathy, with no single pathological feature associated with high sensitivity or specificity. Severe early-onset FGR, overlapping with severe early-onset $\mathrm{PET}$, is mainly associated with features of impaired maternal uteroplacental perfusion secondary to defective extravillous trophoblast invasion, and its consequences. Late-onset FGR probably represents a more heterogeneous group with less characteristic histological changes. Future research using histopathological assessment of aggregated data from multiple studies into larger datasets with centralised pathology review will allow delineation of distinctive clinicopathological associations and further understanding of pathophysiology.

(c) 2014 S. Karger AG, Basel

\section{Introduction}

There has been increasing interest in defining patterns of placental pathology associated with intrauterine fetal growth restriction (FGR), with progressive clinical refinement of subgroups of fetuses that are small for gestational age (SGA), with and without other features of FGR,

\section{KARGER}

E-Mail karger@karger.com www.karger.com/fdt
(C) 2014 S. Karger AG, Basel

1015-3837/14/0362-0117\$39.50/0
Prof. N.J. Sebire

Department of Paediatric Histopathology

Great Ormond Street Hospital

Great Ormond Street, London WC1N 3JH (UK)

E-Mail neil.sebire@ gosh.nhs.uk 
such as abnormal Doppler ultrasound assessment and maternal serum markers such as placental growth factor and fms-like tyrosine kinase-1. Here, we review the available data on documented histopathological features of the placenta associated with early versus late-onset FGR, their significance, and their relationship to findings in pre-eclampsia (PET). We also infer possible pathogenetic implications of these findings and speculate on future work to better define, understand and manage these conditions.

\section{General Placental Histopathological Features Associated with FGR}

There are numerous publications describing a range of morphological features in placentas from pregnancies complicated by FGR (or more specifically SGA, since the vast majority of studies, especially early studies, defined the 'FGR' group simply based on a fetal size below a given centile value rather than definitive features of abnormal fetal growth) [1]. Despite this large descriptive literature, no reliable and pathognomonic features for either FGR/ SGA or specific aetiologies are documented, but several lesions are more common compared to controls in the majority of studies, and hence appear associated with the clinical phenotype of FGR/SGA. However, comparison of findings between different studies, and more detailed analysis of the data, is often not straightforward, due to several reasons. There is biological variation in the disease process due to several complex underlying mechanisms resulting in a final common 'phenotype' of FGR, and individual patient responses may differ in response to a given underlying cause. There is variation in placental morphology due to the fact that FGR occurs in parallel with many features of growth and development of the fetoplacental unit, and there may be geographical variation between different areas of the same placenta in relation to sampling adequacy. In addition, studies may have used different sampling protocols, with associated bias and errors, and the extent of such regional variations in placental histological changes remains undefined. Studies have used different definitions and thresholds for recognising changes as 'lesions', many of which are based on subjective assessment by an observer, such that variation in interpretation between studies is impossible to control. However, the greatest problem is that the study populations examined are relatively poorly defined and potentially heterogeneous. For example, any arbitrary fixed proportion of a population, such as the smallest $5 \%$ of fetuses, will include a mixture of pathologically growthrestricted fetuses and those who are constitutively small, with many studies defining inclusion based on fetal size rather than growth. However, the progressive refinement of clinical subgrouping for inclusion, through use of Doppler studies and plasma biomarkers, has facilitated an improved understanding of FGR pathology, and emerging well-defined subgroups of placental abnormalities are now becoming increasingly recognised.

Despite these potential difficulties in interpretation, there are patterns of placental histological changes that are well reported and common to most studies of the pathology of FGR. First, it should be noted that, overall, approximately one quarter of placentas associated with FGR/SGA (however defined) lack any morphological abnormality on routine macroscopic and histological examination [1]. In those cases with lesions present, the most frequent macroscopic abnormality that occurs with increased frequency in FGR placentas is patchy placental infarction, being present in around $25 \%$ of term FGR versus $10 \%$ of controls [2-14]. This finding illustrates a common theme when interpreting placental findings in FGR, that the frequency of several 'lesions' is increased, but since such lesions are only present in a minority of affected cases and are also found in some normal controls, and since non-FGR is far more frequent than FGR in the population, the positive predictive value of such findings for pathological FGR in any given unselected case will be very low.

Similarly, several microscopic abnormalities have been reported more frequently in FGR placentas, none of which are present in the majority of affected cases in any study, and almost all of which may be encountered in other non-FGR pregnancies, including [2-7, 9-25]: villous infarcts (an example from a placenta in a case of FGR is shown in figure 1a, b), placental abruption/retroplacental haemorrhage, villous morphological abnormalities suggestive of reduced uteroplacental and/or fetoplacental flow ('hypoxic' lesion) such as syncytiotrophoblast 'knots', excess cytotrophoblast cells, thickened trophoblastic basement membrane, villous fibrosis, hypovascular terminal villi, reduced villous volume, reduced intervillous space, and non-specific inflammatory lesions [villitis of unknown aetiology (VUE)]. In addition, histological features indicating defective remodelling of spiral arteries into uteroplacental vessels may be identified, such as inadequate 'physiological change', fibrinoid necrosis and acute atherosis (a dense perivascular lymphocytic infiltrate with intimal arterial foamy macrophages; see fig. 2a, b) [26-28]. 


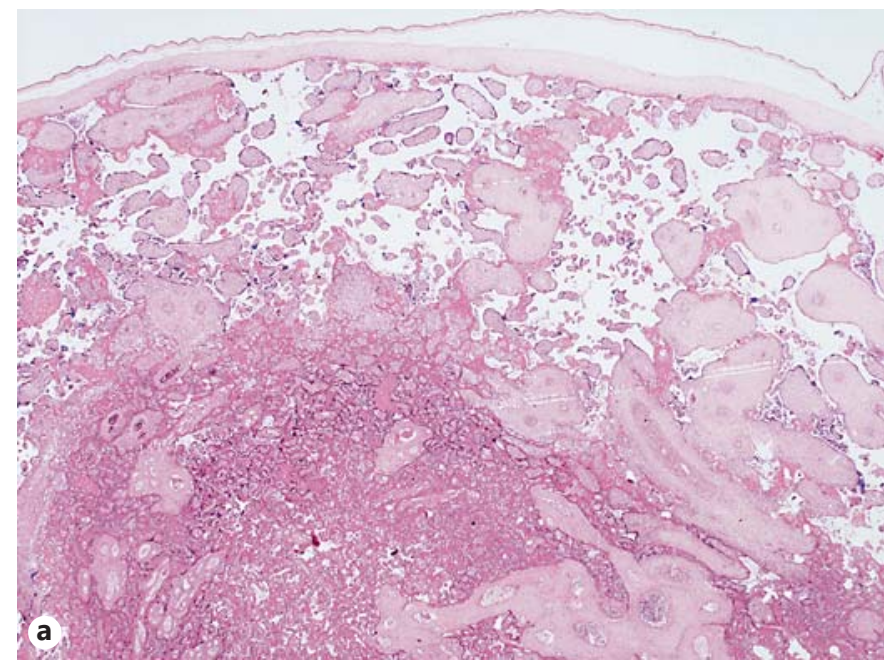

Fig. 1. Placental infarct, secondary to maternal vascular underperfusion. At low magnification (a), the infarct can be seen as an area with severe reduction of the intervillous space and aggregation of villi. In the area surrounding the infarct the intervillous space is increased and there are several very small villi. At higher magnifi-

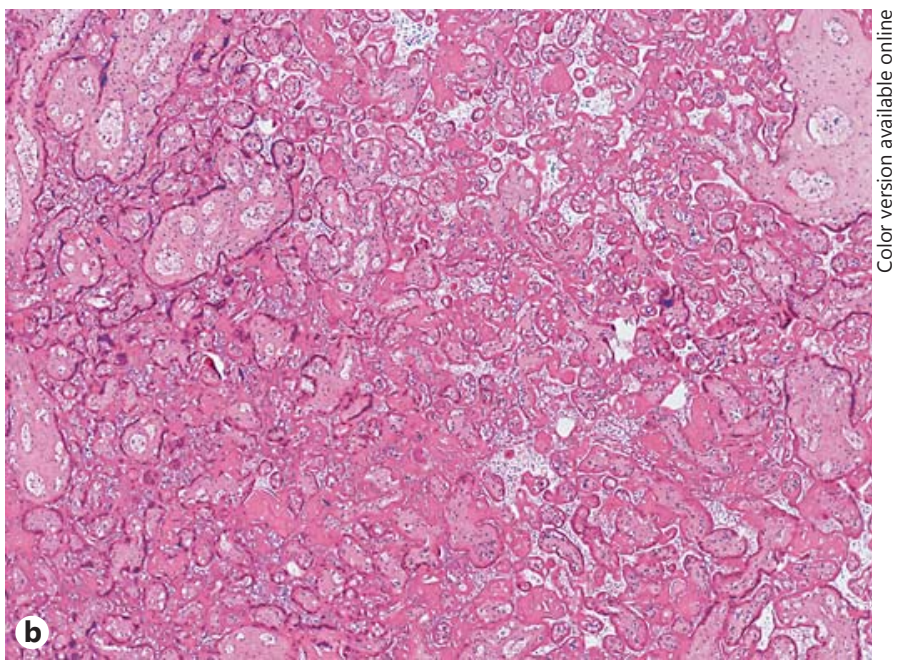

cation (b), villous aggregation can be better appreciated, and the syncytiotrophoblastic show various stages of degeneration, with pyknosis, karyorrhexis and replacement by fibrin-like eosinophilic amorphous (hyaline) material.

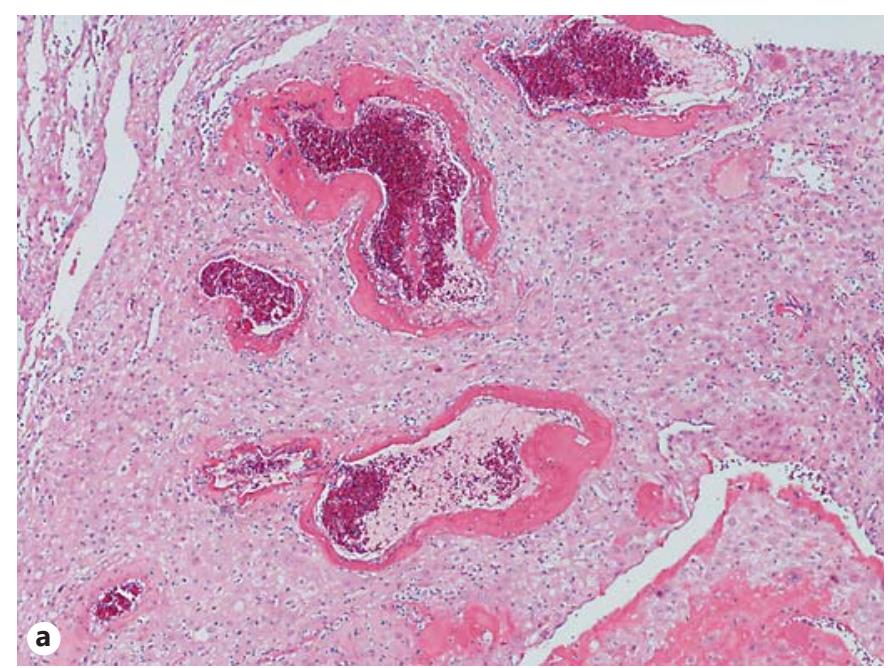

Fig. 2. Lesions of acute atherosis at low (a) and high (b) magnification. The arterial walls are irregular, necrotic and replaced with fibrin-like eosinophilic material. In later stages, there are greater

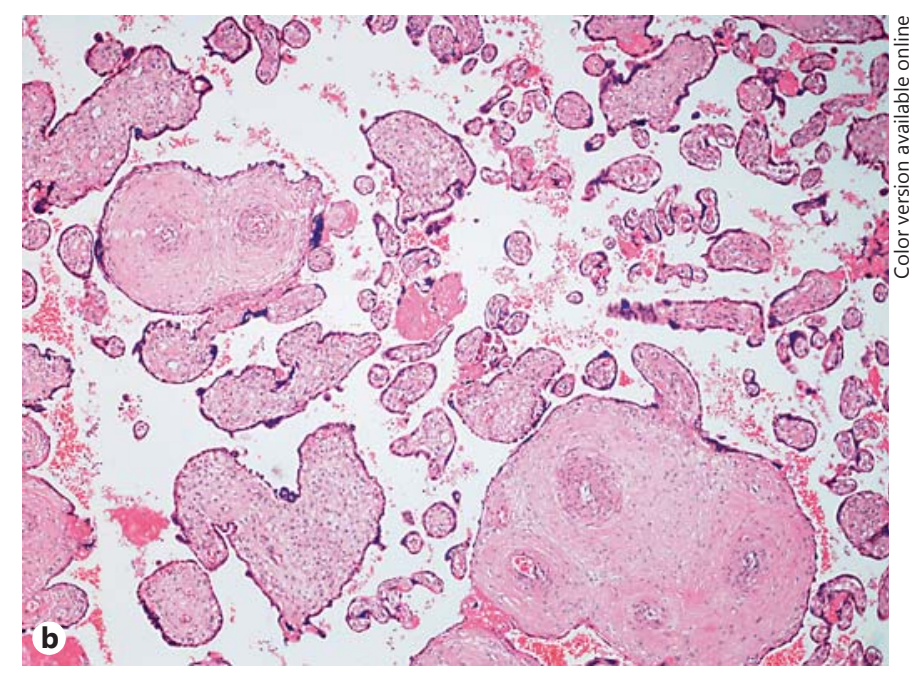

numbers of lipid-laden macrophages (lipophages) and there is a perivascular mononuclear inflammatory infiltrate. These lesions occur in vessels with inadequate extravillous trophoblast invasion.

\section{Association of Placental Pathologies with Clinical Subgroups}

The use of well-defined specific clinical subgroups of definite pathological FGR should allow determination of any specific patterns of placental abnormalities, and hence, suggest pathophysiological pathways. The intro- duction of uterine artery (UtA) Doppler studies identified FGR cases with evidence of maternal uterine malperfusion, with placental bed biopsies in these cases demonstrating defective spiral artery remodelling, including inadequate physiological change and fibrinoid necrosis/ atherosis [27, 29]. Ferrazzi et al. [30] studied placentas from women with FGR and reported that 'extensive hy- 
poxic villous damage' (more than $30 \%$ of terminal villi with one or more of the following: syncytiotrophoblast knotting, excess cytotrophoblast cells, thickened trophoblastic basement membrane, villous fibrosis, hypovascularity), non-peripheral infarcts involving more than 5\% of placental parenchyma, and placental abruption were found only in those FGR cases with abnormal UtA velocimetry, regardless of the presence or absence of pregnancy-induced hypertension (PIH). UtA velocimetry is therefore a marker for defective remodelling of spiral arteries with consequent placental malperfusion and associated impaired fetal growth.

Abnormal UtA Doppler Is Associated with a Common Set of Placental Ischaemic Lesions in FGR and

Preterm PET

The combination of placental bed and parenchymal lesions described in FGR with abnormal UtA velocimetry is essentially identical to lesions described in preterm PET, particularly when subsets of preterm PET and preterm FGR are compared [12, 15, 26, 28-37]. Indeed, abnormally raised UtA resistance is associated with defective trophoblast migration on placental bed biopsies independent of the presence or absence of the clinical syndrome of PIH [38].

Whilst placental findings in preterm PET and FGR are therefore similar, defining the extent of similarity and its dependence on abnormal UtA Doppler would be best achieved by a quantitative meta-analysis, but this is difficult due to the reasons described in the Introduction. Nevertheless, two studies $[12,35]$ were performed by the same group on the same study population (delivering between 22 and 32 weeks' gestation); including 48 cases with FGR $(<10$ th centile); 65\% had PET and in these cases there were significantly greater frequencies of villous fibrosis and hypovascularity. Other lesions occurred at comparable frequency between groups. Table 1 shows a detailed comparison of the pathological findings reported in the two studies. Subsequent data suggests that these features may be associated with reduced end-diastolic flow (EDF) on umbilical artery (UA) Doppler studies [39]. The findings imply a common pathophysiological pathway involving impaired uteroplacental underperfusion in which PET may become apparent in a subset of FGR with placental bed and placental changes.

However, whilst this association is established, the relationship is complex. Regression modelling showed that the abnormal placental histological findings accounted for only $34 \%$ of variation in fetal growth, indicating that histological measures of 'severity' of placental changes do not correlate well with FGR severity [12]. For cases with PET, the predictive value was only around $10 \%$, with histological 'severity' of placental lesions poorly associated with clinical severity of disease [35]. Thus, whilst there is a pattern of placental histological lesions that indicates failure of trophoblast migration, there are no features which are reliably associated with the clinical severity of either PET or FGR.

\section{UA Doppler Abnormalities}

Abnormal UA Doppler indices, particularly absent EDF or reduced EDF, are associated with fetal hypoxia and increased perinatal mortality [30, 40-45]. Such UA abnormalities are progressive and usually accompanied by abnormal UtA velocimetry, which typically develops well before the UA abnormality [45-47]. Within the group of non-hypertensive FGR with abnormal UtA Doppler, UA Doppler abnormalities preferentially identify cases with a high risk of perinatal mortality or morbidity (34\% perinatal mortality with abnormal UA versus no cases of perinatal mortality with normal UA) [30]. Therefore, we can assess whether specific placental lesions are associated with abnormal UA Doppler indices. In the above study, there was no significant difference between groups, but many changes examined reflected abnormal uteroplacental flow rather than aspects of fetoplacental flow, such as fetal stem artery abnormalities, which were not specifically examined. Other studies examining pathology of abnormal UA Doppler have reported an association between FGR and lesions of the fetal stem arteries particularly, including vessel wall thickening/hypertrophy, apparent reduction of vessel lumena and lumenal herniation $[17,39,48,49]$. There appears to be a relationship between the UA pulsatility index and both the proportion of abnormal fetal stem arteries [49] and stem vessel wall thickness $[50,51]$ (see fig. 3). Such stem artery lesions are reported in $90 \%$ of cases with absent EDF (versus 35\% of FGR with present EDF [39]). Interestingly, in cases of reduced EDF, other lesions appear significantly more frequent than in FGR with either normal or absent EDF, including terminal villous fibrosis, hypovascularity, thin-walled stem arteries and haemorrhagic endovasculosis, but the pathological significance of these lesions specifically in relation to flow dynamics is uncertain [39].

The association of UA Doppler abnormalities with small, fibrotic and hypovascular terminal villi was initially proposed to be due to a primary defect in terminal villus development [21, 52-54]. However, it is difficult to explain the coexistence of other changes found in these cas- 
Table 1. Comparison of pathological features in placentas from cases of preterm symmetrical FGR and preterm PET from two comparable studies $[12,35]$

\begin{tabular}{lll}
\hline & Preterm symmetrical & Preterm PET, \% \\
& FGR, \% & \\
\hline Number of cases & 48 & 76 \\
Acute inflammation: amnion* & $\mathbf{8 . 0}$ & $\mathbf{0}$ \\
Acute inflammation: fetal vessels & 10.4 & not reported \\
Chronic villitis & 12.6 & 20.0 \\
Chronic intervillositis & Not reported & not reported \\
Maternal vascular thrombosis: multiple occlusive lesions & 33.3 & 29.0 \\
Maternal vascular thrombosis: single occlusive lesion & 14.6 & not reported \\
Maternal vascular thrombosis: non-occlusive & 6.3 & not reported \\
Chronic maternal vasculitis: $>$ 1 vessel & not reported & 10.0 \\
Chronic maternal vasculitis: 1 vessel only & not reported & 20.0 \\
Absence of spiral artery physiological changes & not reported & 30.0 \\
\hline
\end{tabular}

Fibrinoid necrosis and/or atherosis of spiral arteries: multiple arteries

Fibrinoid necrosis and/or atherosis of spiral arteries: 1 artery only

$$
10.4
$$

Villous fibrosis: severe* 27.

24.0

Villous fibrosis: mild

Villous hypovascularity: severe*

Villous hypovascularity: mild

Villous infarction: multiple

\section{1}

39.6

25.0

39.6

37.5

Villous infarction: single

Villous infarct location: peripheral 10\%

Villous infarct location: central 90\%

Villous infarct location: peripheral \& central

Syncytiotrophoblast knotting: severely increased

Syncytiotrophoblast knotting: mildly increased

Proliferation of cytotrophoblast cells: severe

Proliferation of cytotrophoblast cells: mild

Abruption: frank

Abruption: consistent with

Perivillous fibrin deposition: severely increased

Perivillous fibrin deposition: mildly increased

Fetal vascular thrombosis

'Haemorrhagic endovasculitis'

Avascular terminal villi: multifocal

Avascular terminal villi: focal

Nucleated erythrocytes: numerous

Nucleated erythrocytes: present, not numerous
20.8

10.4

29.2

16.7

39.0

43.8

36.9

27.1

10.4

31.3

45.8

41.7

not reported

not reported

18.8

29.2

17.5

56.3
24.0

82.0

not reported

72.0

not reported

45.0

24.0 ('focal')

11.0

36.0

18.0

40.0

not reported

42.0

not reported

12.0

37.0

43.0

not reported

4.0

12.0

20.0

25.0

76.0

* Parameters with a significant difference between preterm FGR and preterm PET groups, with respective percentages in bold. Percentages are italicised if significantly different from control population used in original study. In the preterm symmetrical FGR study [12], the control population was preterm placentas from pregnancies without FGR (340 cases). In the preterm PET study [35], the control population (353 cases) was a combination of spontaneous premature rupture of membranes (192 cases) and premature labour with intact membranes (161 cases). 


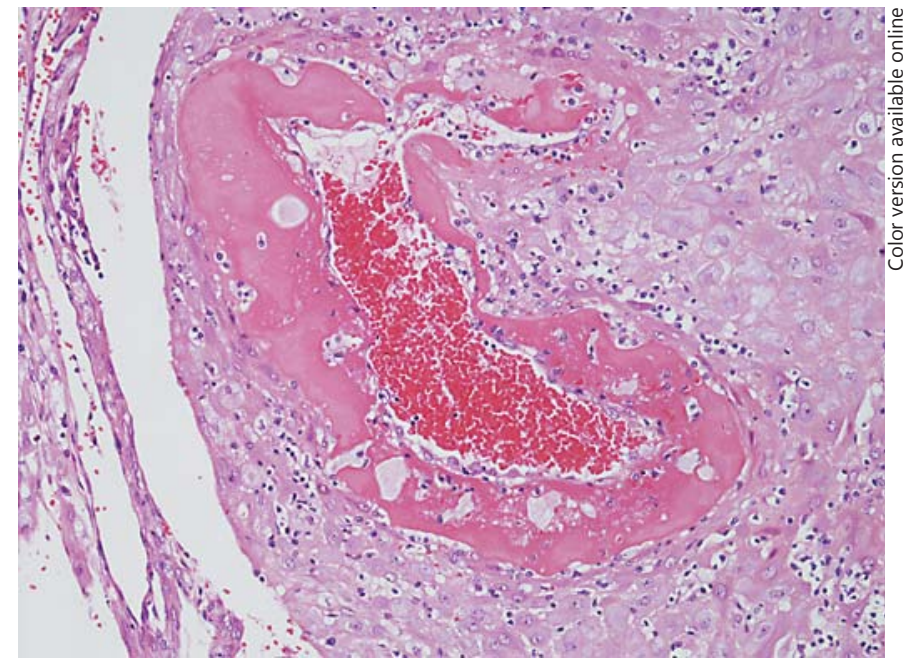

Fig. 3. Fetal stem arteries (within the large villi) showing narrowing of their luminal diameters and thickened walls and associated terminal villous changes of hypovascular, small, straight villi. These changes are associated with abnormal UA Doppler profiles.

es as consequences of such a primary abnormality, and several other lines of evidence suggest that this is erroneous. Changes in the stem villous arteries are strongly suggestive of a response to chronic vasoconstriction [45], and develop in parallel with a progressive UA Doppler abnormality $[45,55]$, and similar downstream changes in terminal villi are present in the territory of an upstream fetal vessel with occlusive thrombus [56, 57]. Importantly, in most cases there is also defective uteroplacental perfusion with associated UtA Doppler studies preceding the UA Doppler changes [46, 47]. Furthermore, experimental evidence in sheep demonstrates a rapid increase in UA resistance upon reducing maternal placental perfusion [58, 59] and there is experimental evidence of rapid and reversible fetal vasoconstriction in the human placenta in response to hypoxia [60], in an analogous manner to the lung, involving inhibition of potassium channels [61]. Similar to the pulmonary circulation, hypoxia-induced and $\mathrm{K}^{+}$channel-mediated depolarisation of vascular smooth muscle cells activates voltage-gated L-type gated $\mathrm{Ca}^{2+}$ channels, which provides cytosolic $\mathrm{Ca}^{2+}$ for activating the contractile apparatus [62]. Such hypoxic vasoconstriction allows autoregulation to optimise fetomaternal flow matching, but when widespread results in increased global flow resistance. However, experimental demonstrations of possible fetal hypoxic vasoconstriction in the placenta have been made with oxygen tensions that are higher than those in the placenta in vivo [60-62], and to the best of our knowledge, no studies have reported the effect of hypoxia at levels approximating those in the placenta, on preparations including the entire fetal subchorionic vasculature. There have been reports studying placental levels of hypoxia on isolated chorionic plate arteries and veins with diameters of $268 \pm 13 \mu \mathrm{m}$ (arteries) and 266 $\pm 19 \mu \mathrm{m}$ (veins) at $2 \%$ oxygen $[63,64]$, showing increased chorionic vein vasodilatation in response to nitric oxide, but no convincing hypoxic chorionic artery vasoconstriction. However, the isolated vessels used in these studies were too large to represent stem villus vessels, whose diameter is typically in the range of $10-100 \mu \mathrm{m}$ in both normal and FGR pregnancies [54]. Regulation of stem venous tone may also occur to maintain water balance [45, $65-$ 67]. To adequately test these hypotheses, one would need an experimental system that can maintain placental cotyledons at physiological levels of oxygenation and also truly representative levels of hypoxia, while allowing for independent variation of intervillous perfusion pressure and for measurement of vascular tone across all the different vessel types (arterial, venous, different calibres). To date, such a system has not been reported.

More recently, the similarity of the changes in the stem villus arteries between severe FGR and preterm PET was further demonstrated by the discovery that in both clinical situations the smooth muscle cells in the stem villus arteries show markedly reduced expression of cystathione-lyase, responsible for synthesis of the potent vasodilator hydrogen sulphide $\left(\mathrm{H}_{2} \mathrm{~S}\right)$. Its reduced expression in the fetal villous resistance vessels supports the view that there is vasoconstriction in the fetal stem villi in association with abnormal umbilical Doppler profile [68]. Interestingly, cystathione-lyase is not only downregulated in cases with abnormal UA Doppler profile, but shows increased expression in PET with normal UA Doppler findings compared to non-PET controls, although expression in both groups appeared heterogeneous by Western blotting. In addition, the PET cases with normal UA Doppler findings were preterm cases (delivered at $29.5 \pm 1.5$ weeks), while the control cases were delivered at term (39 \pm 0.6 weeks) [68].

\section{Other Placental Histological Lesions Associated with FGR}

In addition to the typical uteroplacental and fetoplacental 'vascular' lesions described above, several studies have reported an excess frequency of VUE in FGR, with widely varying rates ranging from 8 to $90 \%[5,11,13,16$, 
$19,69-72]$. VUE is characterised by patchy villous infiltration by chronic inflammatory cells, mainly histiocytes and lymphocytes, especially in basal/maternal floor villi, in the absence of an identifiable infective cause. It is postulated that VUE represents an abnormal maternofetal immune reaction, with consequently increased risk of VUE recurrence [73-77]. VUE is approximately twice as common and more diffuse in multigravidity [78], and it has a higher than expected concordance in twin pregnancies [79]. The pathological features of VUE are well reviewed elsewhere [80], although there is considerable variation amongst 'expert' pathologists in recognising this histological lesion [81]. Nevertheless, there is a consistently increased frequency of VUE in FGR, and also in placentas from cases of PIH and PET, with and without associated FGR, despite the majority of cases being associated with normal pregnancy outcome $[82,83]$. The precise mechanism by which patchy inflammation may lead to impaired fetal growth remains undetermined.

\section{Pathology Associated with Late-Onset FGR and PET}

In the context of the subtypes of FGR defined by Doppler abnormalities, and the similarity of placental findings in early-onset FGR and PET, it is interesting to note increasing recognition of clinical groups of PET with different features and outcomes, Doppler findings, biochemical profile and placental abnormalities.

PET presenting at term is associated with a lower frequency and severity of FGR compared to early-onset PET [84]. This phenomenon could therefore represent either the manifestation of different pathophysiological pathways leading to a similar maternal syndrome in earlyversus late-onset PET, or may represent the same disease process at different stages or rates of evolution. Late-onset PET could therefore be hypothesised to represent a process leading to maternal endothelial damage which is unrelated to impaired early trophoblast invasion, or associated with relatively mild impairment of trophoblastic invasion of the spiral arteries, or with a defect in uteroplacental perfusion that becomes functionally significant only later in gestation, or with similar impairment of trophoblastic invasion to that seen in preterm PET, but with a delayed or reduced maternal response (although this latter explanation would not explain the lower incidence and severity of FGR with late-onset PET). Without definitive evidence for and against these possibilities, it is possible that each may contribute to a proportion of PET with late presentation.

Placenta in Early and Late FGR

\section{Pathological Features}

Multiple studies have reported that placentas from PET presenting at term have a significantly lower frequency of histological lesions associated with impaired maternal uteroplacental perfusion compared to early-onset disease. In an early study of 158 PET placentas there was an inverse relationship between gestation at delivery and the frequency of non-peripheral infarcts, villous hypermaturity and decidual arteriopathy [85] and another study of 37 PET placentas confirmed a significantly reduced frequency of non-peripheral infarcts in cases presenting near term [86]. A large study (with $>900$ PET cases and $>7,000$ controls) also reported an inverse relationship between the frequency of placental lesions of maternal underperfusion (villous infarction, villous agglutination, increased syncytial knots, increased intervillous fibrin, distal villous hypoplasia, persistent vascularisation of basal plate arteries, mural hypertrophy of decidual arterioles, acute atherosis), and gestational age. Despite this inverse relationship, even in PET delivered at or beyond 37 weeks' gestation, the frequency of maternal underperfusion lesions was relatively high at around $30 \%$ [87]. In another series of $>1,200$ PET placentas, a comparable figure of $26 \%$ was reported [88]; in this study, the authors also showed an association of low placental weight $(<10$ th centile) with preterm PET but a converse association of relatively increased placental weight with term PET. What has not been established is any volumetric or proportional extent of placental lesions and how these vary with gestational age at delivery in PET or FGR, since this would require histological study of the entire placenta. In addition, none of these studies reported blinding of the reporting pathologist to the clinical information raising the possibility of reporting bias in retrospective series.

\section{UtA Doppler Profiles}

UtA Doppler abnormalities in the late second trimester are associated with a greater risk of both subsequent PET and FGR, identifying approximately $40 \%$ of PET and $20 \%$ of FGR cases overall, but with the sensitivity for both inversely related to the gestational age at delivery $[89,90]$. These studies report a generally low positive predictive value in screening populations, since the majority (70-90\%) of women with UtA Doppler abnormality on routine screening will not develop PET or FGR [90]. There is no specific study examining histological findings from placentas associated with second trimester UtA Doppler abnormalities and normal versus abnormal fetal outcomes, to determine the relative associations of 
vascular haemodynamic abnormalities versus clinical disease and histological features. When performed in the first trimester, UtA Doppler screening demonstrates a similar inverse relationship between sensitivity and gestational age at delivery, with screening abnormalities significantly associated with preterm PET but not PET at term $[91,92]$.

Abnormal UtA Doppler studies in early pregnancy are therefore more sensitive for identifying women at risk of early-onset preterm PET/FGR, but the majority with an abnormal screen do not develop disease. This indicates that even when UtA flow is abnormal at around the normal time of completion of the second wave of trophoblast invasion, most women appear to have compensatory mechanisms for subsequent uteroplacental flow maintenance. A considerable number of cases of PET develop later in gestation, at or around term [87, 88, 90, 93], and these are predominantly those without significant FGR, who are also much less likely to be predicted by early UtA Doppler screening. (For example, 93\% sensitivity for PET with FGR $<32$ weeks, versus $14 \%$ for PET without FGR delivered at or after 38 weeks, and $50 \%$ for PET with FGR delivered at or after 38 weeks.) These findings either represent that a 'normal' UtA Doppler profile by population data may not be normal for an individual, or that there is a different pathological process leading to at least a subset of term PET, or a combination of explanations. Studies of large cohorts of women with serial UtA Doppler assessments could theoretically address this issue but most current studies, for pragmatic reasons, are based on cross-sectional data from a dynamic developmental process requiring cut-offs derived from population distributions. Blinded standardised histological placental studies in these cohorts with subsequent correlation to Doppler profile evolution patterns as well as to outcome, would allow assessment of associated pathological features.

\section{Abnormal Maternal Serum Biochemistry and Placental Pathology}

There have been several reports of maternal serum biochemical (MSB) differences between early-onset and late-onset PET, which largely reflect the differences noted previously on placental pathological findings and UtA Doppler studies. For example, analysis of serum levels of a number of anti-angiogenic factors, including soluble fms-like tyrosine kinase-1, soluble endoglin and soluble vascular endothelial growth factor receptor-1, and pro- angiogenic factors such as placental growth factor shows an association between preterm PET and high levels of anti-angiogenic factors together with low levels of placental growth factor [94-100]. Those with an 'angiogenic' profile are associated with earlier preterm delivery and adverse outcomes, while non-angiogenic cases are not [100].

The subset of early-onset PET with FGR can therefore be largely defined by the presence of uteroplacental vascular lesions in the placenta, UtA Doppler abnormalities and an anti-angiogenic MSB profile. However, conversely, term PET without FGR demonstrates a general paucity of uteroplacental vascular lesions and absence of a distinctive MSB profile. Within this group there may be some who adapt after an early tendency for uteroplacental underperfusion, and another subset with a similar underlying pathophysiology to more severe cases, but who develop the clinical syndrome more slowly.

\section{Placental Pathology of FGR at Term ('Late-Onset' FGR)}

In keeping with the findings discussed above for PET, whilst placentas from FGR fetuses delivered at term have significantly increased frequencies of uteroplacental vascular lesions (especially infarcts) compared to normal controls, the incidence of such lesions is much lower than in preterm FGR, and many cases are histologically unremarkable [11, 39, 101]. Furthermore, it has been reported that compared to normal term pregnancies, placentas from FGR at term may have an increased incidence of other villous lesions including fibrosis, hypovascularity and avascularity, suggestive of fetal thrombotic events [102], although these changes had not been described in previous studies. In addition, in a minority of cases there is an association with other, non-vascular, pathologies such as VUE $[19,103]$.

FGR at term may therefore include a group of pregnancies with a similar uteroplacental perfusion defect to that seen with early-onset FGR, but with a less severe phenotype, or other changes which may suggest growth restriction mediated via other mechanisms. Interestingly, the majority of this group does not appear to overlap clinically with PET at term, in which the majority are not associated with FGR, despite the fact that both PET/PIH and FGR at term may show similar 'non-specific' placental findings such as VUE. 


\section{Conclusions and Future Directions}

The histological placental findings in FGR are varied, from morphologically unremarkable through to severe uteroplacental vasculopathy, with no single pathological feature associated with high sensitivity or specificity. This is in part because the condition (FGR) is likely heterogeneous, but also because the extent and distribution of disease in the placenta is uneven and there are technical and practical limitations to the methods of routine study of this organ for use in large series. Nevertheless, it is clear that those with severe early-onset FGR, overlapping with severe early-onset PET, are mainly associated with both clinical and histological features of impaired maternal uteroplacental perfusion secondary to defective extravillous trophoblast invasion, and its consequences. Their histopathological findings generally reflect abnormal uteroplacental flow with secondary chronic fetal vascular vasoconstriction and distal villous changes, reflected in abnormal UtA and UA Doppler profiles. Cases of later onset FGR probably represent a more heterogeneous group, are delivered closer to term, and overlap much less with PET at term. These cases may aetiologically represent both a subset of the group with typically more severe disease, in which, for unknown reasons, the effect on the fetus (FGR) and the mother (PET) develops more slowly and/or later and/or to a lesser extent, and those with different aetiologies or mechanisms.

There is room for greater understanding of the mechanisms of FGR/PET based on integration of clinical and pathological data. The parameters that are assessed clinically, biochemically, sonographically and pathologically are subject to substantial variation within a population, only some of which is related to the disease. It is important that future prospective studies of cohorts undergoing serial assessments for FGR have placental examination included into study protocols.

Pathological examination of the placenta remains subject to technological as well as cost and time limitations. It is challenging to interpret the significance of lesions in an organ with large, but variable and imperfectly defined functional reserve. However, current practice can be improved by reporting pathological features in a standardised manner based on published criteria such as maternal vascular underperfusion [104], fetal vascular obstructive lesions [37] and amniotic fluid infection [105], with detailed descriptive and morphometric assessment for study purposes. Furthermore, it is now technically possible for studies using histopathological assessment to upload high-resolution whole-slide images of all material used in a study to a central repository, in a manner analogous to microarray and sequencing data that is deposited in NCBI's GEO $[106,107]$. This suggestion is not new [108], but with the increasing availability and reducing cost of whole slide imaging scanners and low-cost data storage facilities, it is becoming more feasible to implement and would greatly facilitate the aggregation of data from multiple centres into larger studies with centralised pathology review.

\section{References}

1 Fox H, Sebire NJ: The placenta in abnormalities and disorders of the fetus; in Fox H, Sebire NJ (eds): Pathology of the Placenta: Major Problems in Pathology 7, ed 3. Philadelphia, Saunders Elsevier, 2007.

$>2$ Wigglesworth JS: The gross and microscopic pathology of the prematurely delivered placenta. J Obstet Gynaecol Br Emp 1962;69: 934-943.

$>3$ Wigglesworth JS: Morphological variations in the insufficient placenta. J Obstet Gynaecol Br Commonw 1964;71:871-884.

$\checkmark 4$ Wong TC, Latour JP: Microscopic measurement of the placental components in an attempt to assess the malnourished newborn infant. Am J Obstet Gynecol 1966;94:942-950.

5 Altshuler G, Russell P, Ermocilla R: The placental pathology of small-for-gestational age infants. Am J Obstet Gynecol 1975;121:351-359.

6 Sandstedt B: The placenta and low birth weight. Curr Top Pathol 1979;66:1-55.
7 Driscoll SG: Placental lesions. Clin Perinatol 1979;6:397-402.

$>8$ Bjoro K: Gross pathology of the placenta in intrauterine growth restriction. Ann Chir Gynaecol 1981;70:316-322.

-9 Garcia AG: Placental morphology of lowbirth-weight infants born at term. Contrib Gynecol Obstet 1982;9:100-112.

$>10$ Rayburn W, Sander C, Compton A: Histologic examination of the placenta in the growthretarded fetus. Am J Perinatol 1989;6:58-61.

11 Salafia CM, Vintzileos AM, Silberman L, Bantham KF, Vogel CA: Placental pathology of idiopathic intrauterine growth retardation at term. Am J Perinatol 1992;9:179-184.

$\checkmark 12$ Salafia CM, Minior VK, Pezzullo JC, Popek EJ, Rosenkrantz TS, Vintzileos AM: Intrauterine growth restriction in infants of less than thirty-two weeks' gestation: associated placental pathologic features. Am J Obstet Gynecol 1995;173:1049-1057.
13 Oliveira LH, Xavier CC, Lana AMA: Changes in placental morphology of small for gestational age newborns (in Portuguese). J Pediatr (Rio J) 2002;78:397-402.

14 Park S-Y, Kim MY, Kim YJ, Chun YK, Kim HS, Hong SR: Placental pathology in intrauterine growth retardation. Korean J Pathol 2002;36:30-37.

15 Sheppard BL, Bonnar JJ: An ultrastructural study of utero-placental spiral arteries in hypertensive and normotensive pregnancy and fetal growth retardation. Br J Obstet Gynaecol 1981;88:695-705.

16 Labarrere CC, Althabe OO, Telenta MM: Chronic villitis of unknown aetiology in placentae of idiopathic small for gestational age infants. Placenta 1982;3:309-317.

17 Van der Veen F, Fox H: The human placenta in idiopathic intrauterine growth retardation: a light and electron microscopic study. Placenta 1983;4:65-77. 
18 Teasdale F: Idiopathic intrauterine growth retardation: histomorphometry of the human placenta. Placenta 1984;5:83-92.

19 Bjoro K, Myhre E: The role of chronic nonspecific inflammatory lesions of the placenta in intra-uterine growth retardation. Acta Pathol Microbiol Immunol Scand A 1984;92: 133-137.

20 Boyd PA, Scott A: Quantitative structural studies on human placentas associated with pre-eclampsia, essential hypertension and intrauterine growth retardation. Br J Obstet Gynaecol 1985;92:714-721.

-21 Macara L, Kingdom JC, Kaufmann P, Kohnen G, Hair J, More IA, Lyall F, Greer IA: Structural analysis of placental terminal villi from growth-restricted pregnancies with abnormal umbilical artery Doppler waveforms. Placenta 1996; 17:37-48.

-22 Krebs C, Macara LM, Leiser R, Bowman AW, Greer IA, Kingdom JC: Intrauterine growth restriction with absent end-diastolic flow velocity in the umbilical artery is associated with maldevelopment of the placental terminal villous tree. Am J Obstet Gynecol 1996;175: 1534-1542.

-23 Todros T, Sciarrone A, Piccoli E, Guiot C, Kaufmann P, Kingdom J: Umbilical Doppler waveforms and placental villous angiogenesis in pregnancies complicated by fetal growth restriction. Obstet Gynecol 1999;93:499-503.

-24 Sağol S, Sağol O, Ozdemir N: Stereological quantification of placental villus vascularization and its relation to umbilical artery Doppler flow in intrauterine growth restriction. Prenat Diagn 2002;22:398-403.

25 Mayhew TM, Ohadike C, Baker PN, Crocker IP, Mitchell C, Ong SS: Stereological investigation of placental morphology in pregnancies complicated by pre-eclampsia with and without intrauterine growth restriction. Placenta 2003;24:219-226.

26 Brosens IA, Robertson WB, Dixon HG: The role of the spiral arteries in the pathogenesis of preeclampsia. Obstet Gynecol Annu 1972; 1:177-191.

27 Gerretsen GG, Huisjes HJ, Elema JD: Morphological changes of the spiral arteries in the placental bed in relation to pre-eclampsia and fetal growth retardation. Br J Obstet Gynaecol 1981;88:876-881.

28 Khong TY, De Wolf F, Robertson WB, Brosens I: Inadequate maternal vascular response to placentation in pregnancies complicated by pre-eclampsia and by small-for-gestational age infants. Br J Obstet Gynaecol 1986;93: 1049-1059.

29 Olofsson P, Laurini RN, Marsál K: A high uterine artery pulsatility index reflects a defective development of placental bed spiral arteries in pregnancies complicated by hypertension and fetal growth retardation. Eur J Obstet Gynecol Reprod Biol 1993;49:161168.

-30 Ferrazzi E, Bulfamante G, Mezzopane R, Barbera A, Ghidini A, Pardi G: Uterine Doppler velocimetry and placental hypoxic-ischemic lesion in pregnancies with fetal intrauterine growth restriction. Placenta 1999;20:389394.

-31 De Wolf F, Brosens I, Renaer M: Fetal growth retardation and the maternal arterial supply of the human placenta in the absence of sustained hypertension. Br J Obstet Gynaecol 1980;87:678-685.

32 Naeye RL: Pregnancy hypertension, placental evidences of low uteroplacental blood flow, and spontaneous premature delivery. Hum Pathol 1989;20:441-444.

33 Voigt HJ, Becker V: Doppler flow measurements and histomorphology of the placental bed in uteroplacental insufficiency. J Perinat Med 1992;20:139-147.

-34 Roberts JM, Redman CW: Pre-eclampsia: more than pregnancy-induced hypertension. Lancet 1993;341:1447-1451.

35 Salafia CM, Pezzullo JC, López-Zeno JA, Simmens S, Minior VK, Vintzileos AM: Placental pathologic features of preterm preeclampsia. Am J Obstet Gynecol 1995;173:1097-1105.

36 Arias F, Victoria A, Cho K, Kraus F: Placental histology and clinical characteristics of patients with preterm premature rupture of membranes. Obstet Gynecol 1997;89:265271.

37 Redline RW, Ariel I, Baergen RN, Desa DJ, Kraus FT, Roberts DJ, Sander CM; The Society for Pediatric Pathology, Perinatal Section, Fetal Vascular Obstruction Nosology Committee: Fetal vascular obstructive lesions: nosology and reproducibility of placental reaction patterns. Pediatr Dev Pathol 2004;7:443452.

38 Lin S, Shimizu I, Suehara N, Nakayama M, Aono T: Uterine artery Doppler velocimetry in relation to trophoblast migration into the myometrium of the placental bed. Obstet Gynecol 1995;85:760-765.

39 Salafia CM, Pezzullo JC, Minior VK, Divon MY: Placental pathology of absent and reversed end-diastolic flow in growth-restricted fetuses. Obstet Gynecol 1997;90:830-836.

40 FitzGerald DE, Drumm JE: Non-invasive measurement of human fetal circulation using ultrasound: a new method. Br Med J 1977; 2:1450-1451.

-41 Erskine RL, Ritchie JW: Umbilical artery blood flow characteristics in normal and growth-retarded fetuses. Br J Obstet Gynaecol 1985;92:605-610.

42 Trudinger BJ, Giles WB, Cook CM, Bombardieri J, Collins L: Fetal umbilical artery flow velocity waveforms and placental resistance: clinical significance. Br J Obstet Gynaecol 1985;92:23-30.

43 Nicolaides KH, Bilardo CM, Soothill PW, Campbell S: Absence of end-diastolic frequencies in umbilical artery: a sign of fetal hypoxia and acidosis. BMJ 1988;297:1026-1027.

44 Karsdorp VHM, van Vugt JMG, van Geijn HP, Kostense PJ, Arduim D, Montenegro N, Todros T: Clinical significance of absent or reversed end diastolic velocity waveforms in umbilical artery. Lancet 1994;344:1664-1668.
45 Sebire NJ: Umbilical artery Doppler revisited: pathophysiology of changes in intrauterine growth restriction revealed. Ultrasound $\mathrm{Ob}$ stet Gynecol 2003;21:419-422.

46 Campbell S, Pearce JM, Hackett G, CohenOverbeek T, Hernandez C: Qualitative assessment of uteroplacental blood flow: early screening test for high-risk pregnancies. Obstet Gynecol 1986;68:649-653.

47 Bewley S, Cooper D, Campbell S: Doppler investigation of uteroplacental blood flow resistance in the second trimester: a screening study for pre-eclampsia and intrauterine growth retardation. Br J Obstet Gynaecol 1991;98:871-879.

-48 Las Heras J, Baskerville JC, Harding PG, Haust MD: Morphometric studies of fetal placental stem arteries in hypertensive disorders ('toxaemia') of pregnancy. Placenta 1985;6: 217-227.

49 Fok RY, Pavlova Z, Benirschke K, Paul RH, Platt LD: The correlation of arterial lesions with umbilical artery Doppler velocimetry in the placentas of small-for-dates pregnancies. Obstet Gynecol 1990;75:578-583.

50 Mitra SC, Venkataseshan VS, Hagen von S, Barton PT, Delshad G, Gil J: Morphometric study of the placental vessels and its correlation with umbilical artery Doppler flow. Obstet Gynecol 1997;89:238-241.

51 Mitra SC, Seshan SV, Riachi LE: Placental vessel morphometry in growth retardation and increased resistance of the umbilical artery Doppler flow. J Matern Fetal Med 2000;9: 282-286.

52 Hitschold T, Weiss E, Beck T, Hünterfering $\mathrm{H}$, Berle P: Low target birth weight or growth retardation? Umbilical Doppler flow velocity waveforms and histometric analysis of fetoplacental vascular tree. Am J Obstet Gynecol 1993;168:1260-1264.

53 Jackson MR, Walsh AJ, Morrow RJ, Mullen JB, Lye SJ, Ritchie JW: Reduced placental villous tree elaboration in small-for-gestationalage pregnancies: relationship with umbilical artery Doppler waveforms. Am J Obstet Gynecol 1995; 172:518-525.

54 Macara L, Kingdom JC, Kohnen G, Bowman AW, Greer IA, Kaufmann P: Elaboration of stem villous vessels in growth restricted pregnancies with abnormal umbilical artery Doppler waveforms. Br J Obstet Gynaecol 1995; 102:807-812.

55 Turan OM, Turan S, Gungor S, Berg C, Moyano D, Gembruch U, Nicolaides KH, Harman CR, Baschat AA: Progression of Doppler abnormalities in intrauterine growth restriction. Ultrasound Obstet Gynecol 2008;32: 160-167.

56 Redline RW, Pappin A: Fetal thrombotic vasculopathy: the clinical significance of extensive avascular villi. Hum Pathol 1995;26:8085.

57 Kim T-H, Lee H-H, Chung S-H, Park J, Kwak JJ: Fetal thrombotic vasculopathy accompanied by fetal growth restriction. J Matern Fetal Neonatal Med 2013, Epub ahead of print. 
- 58 Stock MK, Anderson DF, Phernetton TM, McLaughlin MK, Rankin JH: Vascular response of the fetal placenta to local occlusion of the maternal placental vasculature. J Dev Physiol 1980;2:339-346.

59 Lang U, Baker RS, Khoury J, Clark KE: Fetal umbilical vascular response to chronic reductions in uteroplacental blood flow in late-term sheep. Am J Obstet Gynecol 2002;187:178186.

60 Howard RB, Hosokawa T, Maguire MH: Hypoxia-induced fetoplacental vasoconstriction in perfused human placental cotyledons. Am J Obstet Gynecol 1987;157:1261-1266.

61 Hampl V, Bíbová J, Stranák Z, Wu X, Michelakis ED, Hashimoto K, Archer SL: Hypoxic fetoplacental vasoconstriction in humans is mediated by potassium channel inhibition. Am J Physiol Heart Circ Physiol 2002; 283:H2440-H2449.

62 Jakoubek V, Bíbová J, Hampl V: Voltage-gated calcium channels mediate hypoxic vasoconstriction in the human placenta. Placenta 2006;27:1030-1033.

-63 Wareing M, Greenwood SL, Taggart MJ, Baker PN: Vasoactive responses of veins isolated from the human placental chorionic plate. Placenta 2003;24:790-796.

-64 Wareing M, Greenwood SL, Baker PN: Reactivity of human placental chorionic plate vessels is modified by level of oxygenation: differences between arteries and veins. Placenta 2006;27:42-48.

65 Sebire NJ, Talbert D: The role of intraplacental vascular smooth muscle in the dynamic placenta: A conceptual framework for understanding uteroplacental disease. Med Hypotheses 2002;58:347-351.

-66 Talbert D, Sebire NJ: The dynamic placenta: I. Hypothetical model of a placental mechanism matching local fetal blood flow to local intervillus oxygen delivery. Med Hypotheses 2004;62:511-519.

67 Sebire NJ, Talbert D: The dynamic placenta: II. Hypothetical model of a fetus driven transplacental water balance mechanism producing low apparent permeability in a highly permeable placenta. Med Hypotheses 2004;62 520-528.

68 Cindrova-Davies T, Herrera EA, Niu Y, Kingdom J, Giussani DA, Burton GJ: Reduced cystathionine $\gamma$-lyase and increased miR-21 expression are associated with increased vascular resistance in growth-restricted pregnancies: hydrogen sulfide as a placental vasodilator. Am J Pathol 2013;182:1448-1458.

69 Mortimer GG, MacDonald DJD, Smeeth AA: A pilot study of the frequency and significance of placental villitis. Br J Obstet Gynaecol 1985;92:629-633.

-70 Nordenvall M, Ullberg U, Laurin J, Lingman G, Sandstedt B, Ulmsten U: Placental morphology in relation to umbilical artery blood velocity waveforms. Eur J Obstet Gynecol Reprod Biol 1991;40:179-190.

71 Salafia CM, Vogel CA, Bantham KF, Vintzileos AM, Pezzullo J, Silberman L: Preterm de- livery: correlations of fetal growth and placental pathology. Am J Perinatol 1992;9:190-193.

72 Redline RWR, Patterson PP: Patterns of placental injury. Correlations with gestational age, placental weight, and clinical diagnoses. Arch Pathol Lab Med 1994;118:698-701.

73 Russell P, Atkinson K, Krishnan L: Recurrent reproductive failure due to severe placental villitis of unknown etiology. J Reprod Med 1980;24:93-98.

74 Redline RW, Abramowsky CR: Clinical and pathologic aspects of recurrent placental villitis. Hum Pathol 1985;16:727-731.

75 Styer AK, Parker HJ, Roberts DJ, Palmer-Toy D, Toth TL, Ecker JL: Placental villitis of unclear etiology during ovum donor in vitro fertilization pregnancy. Am J Obstet Gynecol 2003;189:1184-1186.

-76 Althaus J, Weir EG, Askin F, Kickler TS, Blakemore K: Chronic villitis in untreated neonatal alloimmune thrombocytopenia: an etiology for severe early intrauterine growth restriction and the effect of intravenous immunoglobulin therapy. Am J Obstet Gynecol 2005;193:1100-1104.

77 Perni SC, Predanik M, Cho JE, Baergen RN: Placental pathology and pregnancy outcomes in donor and non-donor oocyte in vitro fertilization pregnancies. J Perinat Med 2005;33: $27-32$.

78 Becroft DM, Thompson JM, Mitchell EA: Placental villitis of unknown origin: epidemiologic associations. Am J Obstet Gynecol 2005; 192:264-271.

79 Jacques SM, Qureshi F: Chronic villitis of unknown etiology in twin gestations. Pediatr Pathol 1994;14:575-584.

80 Redline RW: Villitis of unknown etiology: noninfectious chronic villitis in the placenta. Hum Pathol 2007;38:1439-1446.

81 Khong TY, Staples A, Moore L, Byard RW: Observer reliability in assessing villitis of unknown aetiology. J Clin Pathol 1993;46:208-210.

82 Labarrere C, Althabe O: Chronic villitis of unknown etiology and maternal arterial lesions in preeclamptic pregnancies. Eur J Obstet Gynecol Reprod Biol 1985;20:1-11.

-83 Pathak S, Lees CC, Hackett G, Jessop F, Sebire $\mathrm{NJ}$ : Frequency and clinical significance of placental histological lesions in an unselected population at or near term. Virchows Arch 2011;459:565-572.

84 Odegård RA, Vatten LJ, Nilsen ST, Salvesen KA, Austgulen R: Preeclampsia and fetal growth. Obstet Gynecol 2000;96:950-955.

-85 Moldenhauer JS, Stanek J, Warshak C, Khoury J, Sibai B: The frequency and severity of placental findings in women with preeclampsia are gestational age dependent. Am J Obstet Gynecol 2003;189:1173-1177.

86 Sebire NJ, Goldin RD, Regan L: Term preeclampsia is associated with minimal histopathological placental features regardless of clinical severity. J Obstet Gynaecol 2005;25: 117-118.

87 Ogge G, Chaiworapongsa T, Romero R, Hussein Y, Kusanovic JP, Yeo L, Kim CJ, Hassan
SS: Placental lesions associated with maternal underperfusion are more frequent in earlyonset than in late-onset preeclampsia. J Perinat Med 2011;39:641-652.

88 Nelson DB, Ziadie MS, McIntire DD, Rogers $\mathrm{BB}$, Leveno KJ: Placental pathology suggesting that preeclampsia is more than one disease. Am J Obstet Gynecol 2014;210:66.e1-e7.

89 Papageorghiou AT, Yu CK, Bindra R, Pandis G, Nicolaides KH; Fetal Medicine Foundation Second Trimester Screening Group: Multicenter screening for pre-eclampsia and fetal growth restriction by transvaginal uterine artery Doppler at 23 weeks of gestation. Ultrasound Obstet Gynecol 2001;18:441-449.

90 Papageorghiou AT, Yu CKH, Cicero S, Bower S, Nicolaides KH: Second-trimester uterine artery Doppler screening in unselected populations: a review. J Matern Fetal Neonatal Med 2002;12:78-88.

91 Martin AM, Bindra R, Curcio P, Cicero S, Nicolaides KH: Screening for pre-eclampsia and fetal growth restriction by uterine artery Doppler at 11-14 weeks of gestation. Ultrasound Obstet Gynecol 2001;18:583-586.

92 Melchiorre K, Wormald B, Leslie K, Bhide A, Thilaganathan B: First-trimester uterine artery Doppler indices in term and preterm preeclampsia. Ultrasound Obstet Gynecol 2008; 32:133-137.

$\$ 93$ Scifres CM, Nelson DM: Intrauterine growth restriction, human placental development and trophoblast cell death. J Physiol (Lond) 2009;587:3453-3458.

94 Maynard SE, Min J-Y, Merchan J, Lim K-H, Li J, Mondal S, Libermann TA, Morgan JP, Sellke FW, Stillman IE, Epstein FH, Sukhatme VP, Karumanchi SA: Excess placental soluble fms-like tyrosine kinase 1 (sFlt1) may contribute to endothelial dysfunction, hypertension, and proteinuria in preeclampsia. J Clin Invest 2003;111:649-658.

-95 Levine RJ, Maynard SE, Qian C, Lim K-H, England LJ, Yu KF, Schisterman EF, Thadhani R, Sachs BP, Epstein FH, Sibai BM, Sukhatme VP, Karumanchi SA: Circulating angiogenic factors and the risk of preeclampsia. N Engl J Med 2004;350:672-683.

-96 Chaiworapongsa T, Romero R, Kim YM, Kim GJ, Kim MR, Espinoza J, Bujold E, Gonçalves L, Gomez R, Edwin S, Mazor M: Plasma soluble vascular endothelial growth factor receptor-1 concentration is elevated prior to the clinical diagnosis of pre-eclampsia. J Matern Fetal Neonatal Med 2005;17:3-18.

97 Romero R, Nien JK, Espinoza J, Todem D, Fu W, Chung H, Kusanovic JP, Gotsch F, Erez O, Mazaki-Tovi S, Gomez R, Edwin S, Chaiworapongsa T, Levine RJ, Karumanchi SA: A longitudinal study of angiogenic (placental growth factor) and anti-angiogenic (soluble endoglin and soluble vascular endothelial growth factor receptor-1) factors in normal pregnancy and patients destined to develop preeclampsia and deliver a small for gestational age neonate. J Matern Fetal Neonatal Med 2008;21:9-23. 
-98 Kusanovic JP, Romero R, Chaiworapongsa T, Erez O, Mittal P, Vaisbuch E, Mazaki-Tovi S, Gotsch F, Edwin SS, Gomez R, Yeo L, Conde-Agudelo A, Hassan SS: A prospective cohort study of the value of maternal plasma concentrations of angiogenic and anti-angiogenic factors in early pregnancy and midtrimester in the identification of patients destined to develop preeclampsia. J Matern Fetal Neonatal Med 2009;22:1021-1038.

99 Noori M, Donald AE, Angelakopoulou A, Hingorani AD, Williams DJ: Prospective study of placental angiogenic factors and maternal vascular function before and after preeclampsia and gestational hypertension. Circulation 2010;122:478-487.

100 Rana S, Schnettler WT, Powe C, Wenger J, Salahuddin S, Cerdeira AS, Verlohren S, Perschel FH, Arany Z, Lim K-H, Thadhani R, Karumanchi SA: Clinical characterization and outcomes of preeclampsia with normal angiogenic profile. Hypertens Pregnancy 2013;32:189-201.
101 Apel-Sarid L, Levy A, Holcberg G, Sheiner E: Term and preterm $(<34$ and $<37$ weeks' gestation) placental pathologies associated with fetal growth restriction. Arch Gynecol Obstet 2010;282:487-492.

102 Kovo M, Schreiber L, Ben-Haroush A, Wand S, Golan A, Bar J: Placental vascular lesion differences in pregnancy-induced hypertension and normotensive fetal growth restriction. Am J Obstet Gynecol 2010;202: 561.e1-e5.

103 Althabe O, Labarrere C: Chronic villitis of unknown aetiology and intrauterine growthretarded infants of normal and low ponderal index. Placenta 1985;6:369-373.

104 Redline RW, Boyd T, Campbell V, Hyde S, Kaplan C, Khong TY, Prashner HR, Waters BL, Society for Pediatric Pathology, Perinatal Section, Maternal Vascular Perfusion Nosology Committee: Maternal vascular underperfusion: nosology and reproducibility of placental reaction patterns. Pediatr Dev Pathol 2004;7:237-249.
05 Redline RW, Faye-Petersen O, Heller D, Qureshi F, Savell V, Vogler C: Amniotic infection syndrome: nosology and reproducibility of placental reaction patterns. Pediatr Dev Pathol 2003;6:435-448.

106 Edgar R, Domrachev M, Lash AE: Gene Expression Omnibus: NCBI gene expression and hybridization array data repository. $\mathrm{Nu}-$ cleic Acids Res 2002;30:207-210.

107 Barrett T, Wilhite SE, Ledoux P, Evangelista C, Kim IF, Tomashevsky M, Marshall KA, Phillippy KH, Sherman PM, Holko M, Yefanov A, Lee H, Zhang N, Robertson CL, Serova N, Davis S, Soboleva A: NCBI GEO: Archive for functional genomics datasets - update. Nucleic Acids Res 2013;41:D991-D995.

108 Hipp JD, Lucas DR, Emmert-Buck MR, Compton CC, Balis UJ: Digital slide repositories for publications: lessons learned from the microarray community. Am J Surg Pathol 2011;35:783-786. 